Territorios 39 / Bogotá, 2018, pp. 47-70

ISSN: 0123-8418

ISSNe: 2215-7484

La diversidad de la securización urbana: dimensiones, actores y retos

\title{
Suelos securitarios. Hacia una antropología urbana de las asociaciones vecinales por la seguridad en la ciudad de La Plata, Argentina*
}

Grounded Security. Towards an Urban Anthropology of Neighborhood Associations for Security in the City of La Plata, Argentina

Solos securitários. Para uma antropologia urbana das associações vicinais pela segurança na cidade de La Plata, Argentina

Joaquín Vélez ${ }^{* *}$

Recibido: 15 de noviembre de 2017

Aprobado: 11 de abril de 2018

Doi: http://dx.doi.org/10.12804/revistas.urosario.edu.co/territorios/a.6248

Para citar este artículo:

Vélez J. (2018). Suelos securitarios. Hacia una antropología urbana de las asociaciones vecinales por la seguridad en la ciudad de La Plata, Argentina. Territorios (39), 47-70. Doi: http://dx.doi.org/10.12804/revistas. urosario.edu.co/territorios/a.6248

* Este trabajo no hubiera sido posible sin el otorgamiento de una Beca Doctoral del Consejo Nacional de Investigaciones Cientificasy Técnicas (Conicet) de Argentina, en el marco de la cual me encuentro realizando el Doctorado en Antropología Social del Instituto de Altos Estudios Sociales de la Universidad Nacional de San Martín. Agradezco especialmente las correcciones de los/as evaluadores/as anónimos/as de la revista Territorios, los comentarios y aportes de compañeros/as $y$ colegas de dicho posgrado, como a quienes pertenecen al Laboratorio de Estudios en Cultura y Sociedad de la Facultad de Trabajo Social, Universidad Nacional de La Plata (UNLP); también a los fructiferos diálogos compartidos con Luisina Bolla. Las valiosas 
Palabras clave

Vecinos en alerta, (in)seguridad, antropología urbana, objetos técnicos, gubernamentalidad, control, La Plata.

Keywords

Neighbors on alert, (in)security, urban anthropology, technical objects, governance, control, La Plata.

Palavras-chave

Vizinhos em Alerta, (in) segurança, antropologia urbana, objetos técnicos, governabilidade, controle, La Plata.

\section{territarias 39}

\section{RESUMEN}

Este trabajo se propone reflexionar e indagar sobre diversas dimensiones en las que se manifiesta y construye el problema de la (in)seguridad y su gestión por diferentes actores. Para ello, se hará un foco en el espacio urbano delimitado por la ciudad de La Plata y en algunas organizaciones actuales, como Vecinos en alerta, Asambleas por la seguridad y otros emergentes, a partir de un trabajo de campo etnográfico que involucra usos de mensajería instantánea, políticas y agendas públicas y reflexiones metodológicas sobre el ejercicio de la etnografía en estos contextos. Una de las preguntas centrales de esta investigación, se entronca en el esfuerzo que existe en ámbitos académicos y políticos para comprender ciertas tendencias hacia una securización de la agenda pública y formas novedosas de gubernamentalidad, en parte marcadas por tendencias electorales conservadoras. En este sentido, en las sociedades definidas por algunos como 'posneoliberales' (Sozzo, 2016), queda aún por comprender ciertos suelos culturales (Kusch, 2007) y condiciones de posibilidad (Tiscornia, 2004) para que los discursos de inflacionismo penal y populismo punitivo, las prácticas de linchamiento y las diferentes formas de represión policial, que parecen estar en alza, sean compuestos. En una primera parte se abordarán problemas conceptuales y generales de la región para luego hacer foco en los casos y trabajo de campo que aquí competen.

\section{ABSTRACT}

The comprehension of the different dimensions, modes and manners in which urban policing and the securitarian problem is built, is the task this paper intends to achieve. In this sense, we will focus in the urban space of La Plata city, its peripheries and the various actors related to neighborhood watch and community safety. We will intend an ethnographical approach in a fieldwork that includes instant messaging applications, public polices, agenda and methodological considerations. In this sense, we take part in the efforts that exist in academical and political domains, in order to explain the protagonist role of policing demands, and new forms of governmentality, signed by conservative electoral tendencies. In societies defined as "postneoliberals" (Sozzo, 2016), the question about the cultural groundings (Kusch, 2007) and conditions of possibilities (Tiscornia, 2004) for repressive discourses and practices to expand and be composed, remains inhabited. General and conceptual problems related to the region will be the first topic, while the second part will focus in the fieldwork in course with neighbor ensembles and associations, being produced inside the limits of La Plata city.

\section{RESUMO}

Este trabalho propõe reflexionar e indagar sobre as diversas dimensões nas que se manifesta e constrói o problema da (in)segurança e sua gestão por diferentes atores. Para isto, nos focalizaremos no espaço urbano delimitado pela cidade de La Plata e em algumas organizações atuais, como Vizinhos em alerta, Assembleias pela segurança e outros emergentes, a partir de um trabalho de campo etnográfico que envolve usos de mensagens instantâneas, políticas e agendas públicas e reflexões metodológicas sobre o exercício da etnografia nestes contextos. Uma das perguntas centrais desta pesquisa entronca-se no esforço que existe em âmbitos acadêmicos e políticos para compreender certas tendências para uma segurança da agenda pública e formas novas de 
governabilidade, em parte marcadas por tendências eleitorais conservadoras. Neste sentido, nas sociedades definidas por alguns como "pós-neoliberais" (Sozzo, 2016) fica ainda por compreender certos solos culturais (Kusch, 2007) e condições de possibilidade (Tiscornia, 2004) para que os discursos de inflacionismo penal e populismo punitivo, as práticas de linchamento e as diferentes formas de repressão policial que parecem estar em subida, sejam compostos. Nos ocuparemos em uma primeira parte de problemas conceituais e gerais da região para depois nos enfocar nos casos e trabalho de campo que aqui nos competem.

\section{Introducción}

Una de las principales discusiones del campo criminológico se relaciona con lo que Dario Melossi (2001) ha denominado cultural embeddedness (anclaje cultural) del control social, para contextualizar y situar los problemas vinculados con el crimen y los usos de las violencias, cuestión que había sido problematizada en los casos de 'gatillo fácil' por Sofía Tiscornia (2004). Aunque muchos/as autores/as reconozcan la importancia del consenso social para la legitimidad del uso de la fuerza, esto es, que sin 'olfato social' no hay 'olfato policial' (Rodríguez, 2014), pareciera que - a pesar de la 'opacidad' constitutiva de los policiamientos - actualmente proliferan más estudios del segundo que del primero y, tanto las instituciones como los sujetos destinatarios de la coacción suelen ser priorizados en los análisis: "Recientemente, Garland mismo ha reconocido [...] que algunas de las narrativas que tratan de explicar los cambios penales -incluyendo la suya propia - no han abordado adecuadamente los procesos específicos que 'traducen' las causas sociales en resultados penales [...]" (Sozzo, 2016, p. 19). ¿Por qué no ahondar en estos sectores y situar otras perspectivas, sin caer en el holismo funcionalista ni en la ilusión de la aldea en la ciudad (Gorelik, 2008b) pero retomando la importancia de entender lo normativo en lo cotidiano? (Malinowski, 1987; Douglas, 1994; De Certeau, 2000). Entonces, ¿̇ómo se puede heurísticamente dimensionar lo que es vivir en una 'vecinocracia' (Rodríguez, 2014) del lado de adentro? ¿Cómo reconstruir la perspectiva del actor y seguir el hilo de la experiencia?

Para ahondar en este giro, es que se lleva adelante la aplicación de un abordaje antropológico y etnográfico que propone dar cuenta cómo es que se producen estos suelos securitarios en los que gravitan discursos, prácticas y objetos en torno a la securización de la trama urbana. El objetivo más amplio de esta investigación consiste en dar cuenta de los modos de construcción del espacio urbano y las asociaciones que se producen en torno a la inseguridad en la ciudad de La Plata. El trabajo de campo y las prospecciones iniciales en dicho espacio comenzaron a partir de abril de 2016, continuándose hasta el momento de escribir el presente trabajo. ${ }^{1}$ Durante su curso, se exploraron correcciones del Dr. Ramiro Segura me ayudaron a mejorar muchos aspectos del presente trabajo, cuyas posibles deficiencias y puntos endebles quedan bajo mi entera responsabilidad.

** Laboratorio de Estudios en Cultura y Sociedad, Facultad de Trabajo Social, Universidad Nacional de La Plata. CONICET. Correo electrónico:jv9891@gmail. com. ORCID: http://orcid. org/0000-0001-9108-5529

1 Previamente contaba con mi residencia en la ciudad de La Plata desde aproximadamente el 2010 de forma relativamente continuada, por lo que el espacio urbano no me era extraño, y participé de la tarea de extrañar la propia cotidianidad y problematizar sentidos comunes en aras de desnaturalizar y reflexionar sobre las formas incorporadas de habitar la ciudad.

territarias 39

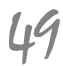


diferentes posiciones en la construcción de datos que se pueden situar entre el polo de la observación participante, como de la participación observante, y el intento de explorar registros y soportes materiales no tradicionales, como son el de la mensajería instantánea, las publicidades de políticas públicas y propaganda electoral.

En este sentido, uno de los resultados parciales de la presente investigación se vincula con las formas de asociación informal que, por medio de las relaciones de vecindad, construyen parte de su acceso a la ciudadanía y a la construcción de una interlocución que intenta interpelar, desde estos miedos y subjetivaciones, a las agencias estatales, a la vez que produce transformaciones arquitectónicas y urbanas (Segura, 2009) por las tecnologías de vigilancia pública y privada. Dicho abordaje etnográfico permite encontrar las asociaciones inesperadas, los sentidos soterrados, ambiguos; las potencias insospechadas que se producen en la actualización de las redes y las formas de habitar el espacio urbano asociadas con la inseguridad (Segura, 2006). Problemas con los servicios de agua corriente, luz, gas, televisión por cable, inundaciones, podas, mascotas perdidas, casos de violencia de género o colectas barriales, se entrelazan con las demandas y soportes de las redes securitarias, funcionando, por la legitimidad y efectismo, como una especie de caballo de Troya donde se incorporan, subrepticiamente, otras demandas por las formas del malestar en la ciudad.

\section{Interrogando el problema securitario}

En las últimas décadas, los debates acerca de la inseguridad y los riesgos de la vida urbana se han instalado entre los principales tópicos de la agenda pública. En todos los países de América Latina, la seguridad y el delito se encuentran entre los problemas centrales detectados en las encuestas de opinión pública. Aún en países con menores tasas de delitos, también aparecen entre los primeros tópicos, dado que las tasas de victimización reconocen una cierta autonomía relativa, que muestra índices similares (y altos) más allá de las variaciones en las tasas de delitos y homicidios (Kessler, 2009; Kessler \& Merklen, 2013). A su vez, incluso en países gobernados por coaliciones de centroizquierda o movimientos populares, las tasas de población penitenciaria han aumentado significativamente. Así, se encuentran gobiernos denominados progresistas con políticas de seguridad represivas y “duras", lo cual presenta paradojas sobre sus modelos de estado y acumulación: progresistas en muchas áreas, no lo han conseguido en materia securitaria, aún cuando haya habido variados intentos de reformas (Sozzo, 2016; Saín, 2017). De hecho, se observa actualmente un neopunitivismo diferente al de los noventa, con gran control mediante dispositivos y formas de habla sobre el crimen (Caldeira, 2007) que se han impuesto casi como suelo, no siendo capaz el garantismo

\section{territarios 39}


y otras corrientes criminológicas críticas de construir una nueva hegemonía. Por otro lado, las propuestas abolicionistas o de sectores de izquierdas que levantan como emblema el desmantelamiento del aparato represivo, no consiguen construir alternativas viables; ya que la paradoja que presentase Pier Paolo Passolini sobre el aparato coercitivo en casos de toma revolucionaria del poder, así como el concepto clásico de dictadura del proletariado, precisan mantener el poder de policía para ser llevados adelante (Rodríguez, 2016; Sozzo, 2005 ). En otros casos en los que se ha apelado a formas comunitarias de resolución de conflictos, esto tiene alcance solo para algunos tipos de delitos que tienen poca incidencia en decisiones estructurales y de conjunto, como se ha dado con la Constitución Social y la formación del Estado Plurinacional de Bolivia (Rivera, 2014).

Es así que el paradigma securitario (Rodríguez, 2014) y el problema del pasaje de las sociedades disciplinarias a las sociedades de control o seguridad (Christie, 2007; Foucault, 2007) -Font (1999) traduce "campo de gobierno de la inseguridad" del "policing" anglosajón (Shearing, 1995)lleva a reflexionar sobre ciertos tópicos: qué mecanismos se ponen en práctica y se superponen en los diferentes modos de pensar el espacio público y lo social (Gorelik, 2008a); la aparición de nuevos actores sociales y figuras como la del vecino (Frederic, 2004, Grimson 2009); la forma en que estas nociones y prácticas se espacializan, es decir, se traducen en disposiciones espaciales y temporales (Segura \&
Chaves, 2015; Hannerz, 1986; Monghin, 2006) de flujos y cortes (Deleuze, 2005), de regulaciones sobre qué es lo que pasa y qué es lo que no pasa (Latour, 2013). En este sentido, para abordar etnográficamente las relaciones entre prácticas y territorios en torno a la (in)seguridad entre vecinos y vecinas de la ciudad de La Plata sobre las que reflexiona el presente trabajo, seguimos heurísticamente la "[...] doble negación que orientaría la investigación: el espacio urbano no es un mero contexto de localización de las prácticas sociales y, simultáneamente, el espacio urbano no determina (o agota) las prácticas sociales" (Segura \& Chaves, 2015, p. 14). Interesa a su vez entender el miedo como "una experiencia individualmente experimentada, socialmente construida y culturalmente compartida" (Reguillo, 2000, p. 189), experiencia denominada por Rotker (2000) "ciudadanía del miedo" entendida como "la nueva subjetividad, la nueva forma de relación comunitaria” (p. 23), que pone en evidencia el carácter paradojal y controversial de la sociabilidad que implica una ciudadanía, que por un lado pretende aparecer como garante de los derechos en una democracia formal, cuando por el otro se sostiene con base en una sistemática exclusión y negación de ciertos sectores.

\subsection{Inseguridad en América Latina}

Como se ha mencionado, la instalación pública del problema de la seguridad ciudadana, definido como el "problema de la inseguridad" o del delito (generalmente territarias 39

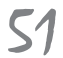


2 Personalmente, formo parte de una organización de territorial en la Provincia de Buenos Aires que trabaja con niños/as y jóvenes de sectores vulnerados en territorios donde se están evidenciando casos de tortura con picana eléctrica, mayor participación en las redes de narcotráfico, trata de personas, complicidad en casos de femicidios y abusos sexuales, etc.

${ }^{3}$ Esto asociado con una idea de ciudadano-consumidor y a la responsabilidad de la propia persona sobre su situación, que permea la matriz (pos) neoliberal actual.

\section{tersitarias 39}

utilizado como término no marcado de aquellos delitos contra la propiedad y la persona en general, manteniendo sesgos - al menos - clasistas, patriarcales, racistas y etarios) es uno de los ejes más importantes registrados en encuestas a lo largo América Latina (Kessler, 2011). Según Naciones Unidas, las tasas de homicidios en la región solo son superadas por el sur de África, mientras que datos de hace menos de una década indicaban que América Latina concentraba aproximadamente un $12 \%$ de la población mundial, menos del $4 \%$ de armas de fuego en manos de civiles y un $40 \%$ de los homicidios cometidos con este tipo de armas (Karp, 2009 citado en Kessler \& Merklen, 2013). La violencia policial es un problema bastante extendido, con un contexto social que está naturalizando cada vez más los abusos y usos discrecionales de los aparatos represivos de Estado, ${ }^{2}$ lo que sugiere una tendencia en los modelos disciplinarios y de gestión de la vida al interior de estos Estados nación.

Las teorías que han intentado explicar estas relaciones en términos de pobreza absoluta (que han permeado buena parte de las políticas públicas de la década del noventa) y su tendencia a la focalización sobre grupos marginados no han podido explicar cómo en prácticamente todas las zonas donde las condiciones de vida han mejorado en términos materiales, los índices de crímenes y homicidios no lo han hecho. En cambio, sí se ha encontrado una cierta relación en los índices de desigualdad social y desempleo vinculado con los delitos contra la propiedad privada, así como bajas en las tasas cuando existe una mayor inversión estatal en políticas sociales y obra pública en relación con las necesidades básicas (Kessler, 2013) y no solo un aumento de la capacidad de consumo de amplios sectores postergados, uno de los objetivos principales de las políticas de los últimos 15 años en la región. ${ }^{3}$ Estas diversas aristas intentan señalar que América Latina se constituye como el territorio con mayor desigualdad relativa del mundo, y a la vez el que cuenta con mayores índices de violencia cotidiana, concentrando 25 de las 27 ciudades con mayores tasas de homicidios (Kessler, 2011) y un aumento constante de las tasas de femicidios y feminicidios, sistemáticamente invisibilizadas por estadísticas oficiales, que alcanza la envergadura de un genocidio (Segato, 2016). De todas formas, la relación entre desigualdad social y tasas de delito tampoco es lineal y merece ser problematizada: en una sociedad como la venezolana, las desigualdades socioeconómicas han disminuido casi tan notablemente como han aumentado prácticamente todas las formas de violencia; Cuba tiene una tasa de encarcelamiento similar a la estadounidense; o Uruguay, el país con menos desigualdad del Cono Sur, pero con la mayor proporción de policías por cantidad de habitantes acompañado también de altas tasas de encarcelamiento. En la Argentina, actualmente, se está evidenciando un gran crecimiento de la presencia policial efectiva, así como de las formas de prevención y control en su gestión pública y privada (Lorenc Valcarce, Esteban \& Guevara, 2012; Sozzo, 2016). Ello pareciera implicar nuevas 
maneras de disponer los policiamientos y técnicas de gubernamentalidad (Foucault, 2007). En los casos trabajados en esta investigación, las discusiones vecinales en torno a la instalación de dispositivos de seguridad como cámaras y alarmas por empresas privadas, el pago de "incentivos" a las fuerzas policiales o la contratación de personal de seguridad privada, forman parte del repertorio de acciones que despliegan algunos sectores, lo que hace proliferar una forma de consumo securitario, tanto de objetos y servicios, como de medios gráficos y audiovisuales.

La relativa socavación de larga duración de los vínculos interpersonales y comunitarios en las grandes urbes en una expropiación y redefinición del capital social por la constitución de los estados modernos, unido a una importantísima participación de las fuerzas represivas en la gestión de economías y mercados ilegales - en Argentina, particularmente, ya que los grandes grupos de crimen organizado no tienen suficiente poder como para operar sin la venia policial (Saín, 2017)— continuó produciendo una fuerte deslegitimación del "Estado", aun cuando se hubiesen conseguido mejoras relativas en otros ámbitos dentro de modelos de estado no plenamente neoliberales, aunque de matrices extractivistas en la división neocolonial de la producción mundial. De esta forma, las figuras de las víctimas, vecinos y vecinas son más inteligibles como figuras legítimas del campo de lo político, como ha trabajado la antropóloga argentina Sabina Frederic (2004) en su trabajo
"Buenos vecinos y malos políticos. Moralidad y política en el Gran Buenos Aires". Ante la falta de confianza y de respuestas en las autoridades estatales, las formas de auto-organización han proliferado ${ }^{4}$, como también lo hicieron en un contexto muy distinto las asambleas vecinales luego de las crisis del 2001 y el "Argentinazo". ${ }^{5}$ Esto ha tenido como suelo también la relevancia de los barrios y territorios habitados, hacia donde se replegaron las formas políticas, una vez que los anclajes identitarios en relación con el trabajo fueron debilitados en la década del noventa (Grimson, 2009). En relación con la identificación de vecino, Segura (2009) señala que "además de un criterio de localización - necesario, pero insuficiente- la categoría nativa vecino remite a ciertas "dimensiones morales" y de reconocimiento. Así, muchos residentes del barrio no son vecinos y, por ende, parecerían no ser ciudadanos" (p. 73). Esta condición de acceso se encuentra en las asambleas vecinales mapeadas, donde solo algunos/as son considerados bajo esta rúbrica, por lo que será preciso también delimitar cuáles son en cada caso esas condiciones de adscripción.

Por otro lado, en una investigación colectiva que estamos llevando adelante con un grupo interdisciplinario de la $\mathrm{Fa}$ cultad de Trabajo Social de la Universidad Nacional de La Plata, ${ }^{6}$ a partir de unas ochenta entrevistas sobre vida urbana en el corredor sur de la Región Metropolitana de Buenos Aires, orientadas a partir de un muestreo teórico de diferentes tipos sociourbanos y clivajes sociales, la
${ }^{4}$ Se han relevado constantemente acontecimientos disruptivos que traccionan ensambles vecinales para movilizarse en torno a la seguridad con relaciones ambivalentes y complejas con las distintas agencias del Estado, y que suelen ser difundidas por medios masivos de comunicación, como se relata en el caso platense.

${ }^{5}$ Entre las asociaciones vecinales en torno a la inseguridad relevada, la Asamblea Vecinal de Barrio Norte fue fundada en febrero del 2002 y se ha mantenido desde entonces con diferentes temasy dinámicas, ocupándose más especificamente de problemas securitarios desde comienzos del 2017.

6 "La experiencia metropolitana del corredor sur de la RMBA: dominios urbanos, espacialidad y temporalidad en actores sociales con posiciones desiguales en la metrópoli" (PICT 20121270, Agencia Nacional de Promoción Científica y Tecnológica).

territarias 39

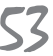


inseguridad aparece como uno de los tópicos más relevantes, organizando lógicas y dinámicas para el uso del espacio y la temporalidad en la ciudad, la elección de las zonas y tipos de residencia y expectativas de futuro. Muchos de estos actores organizan su propia vigilancia y las redes que se establecen entre personas (no) afines con el objetivo de regular y controlar el espacio urbano. Sin embargo, el significante seguridad tampoco ha sido homogéneo ni se ha asociado con los mismos imaginarios, invisibilizando sentidos de las conciencias prácticas de los actores (Rotker, 2000; Varela, 2005). Es así necesario reponer la disputa misma por la definición del término en el campo, identificar usos nativos y la formas en que la (in)seguridad media la experiencia social, para poner entre paréntesis los discursos presentes en la socialidad cotidiana y ocupar una posición de extrañamiento que permita indagar qué otras dimensiones y multiplicidades toman sus (no) lugares en la vida urbana.

Una vez presentados los contextos y conceptos que guiarán este trabajo, estamos en condiciones de problematizar las redes de "ciudadanos/as" y "vecinos/ as" en relación con la gestión del espacio urbano, para observar cómo se producen ensambles entre humanos y no-humanos (Latour, 2008) en dichas redes, y cómo fuerzan cambios y disposiciones relevantes para la regulación de las personas. Algunas líneas recuerdan, como tempranamente planteaba Karl Marx (1991), la importancia de la seguridad y de los marcos que brindan el Estado de derecho, la legalidad y el poder de policía para que la propiedad privada y la fuerza de trabajo tengan su posibilidad de (re)producción. La incorporación de nuevas tecnologías para mediar y estabilizar/potenciar relaciones y producir espacios proporciona nuevas formas de estar en el mundo en las que se hacen posibles estos cambios, como en el caso de los grupos de mensajería instantánea (WhatsApp) que se forman como modo de comunicación, coordinación y control, con dinámicas y registros en cierta forma novedosos. Es así que apostamos a una mirada composicionista (Latour, 2013) y pragmática que pueda rastrear el hilo de la experiencia: ¿qué procesos de subjetivación (individuales, familiares, colectivos) tienen lugar en una sociedad cada vez más puertas adentro?

A continuación, se hará una breve caracterización del territorio delimitado por las ciudades de La Plata y Gran La Plata para arribar a las asociaciones en torno a la inseguridad.

\section{Caracterizando \\ a La Plata, ubicando el campo. Campañas, políticas y asambleas contra la inseguridad}

Esta segunda sección se centra en el espacio relevado, las aproximaciones etnográficas y distintos soportes y registros que hacen a la construcción, circulación y vivencia de la experiencia securitaria.

La ciudad de La Plata es la capital de la provincia de Buenos Aires, desde que fue planificada, diseñada y fundada en 1882 a ese 
Figura 1. Ubicación de la Ciudad de La Plata en el territorio de la República Argentina y ampliación de su situación en la Región Metropolitana de Buenos Aires

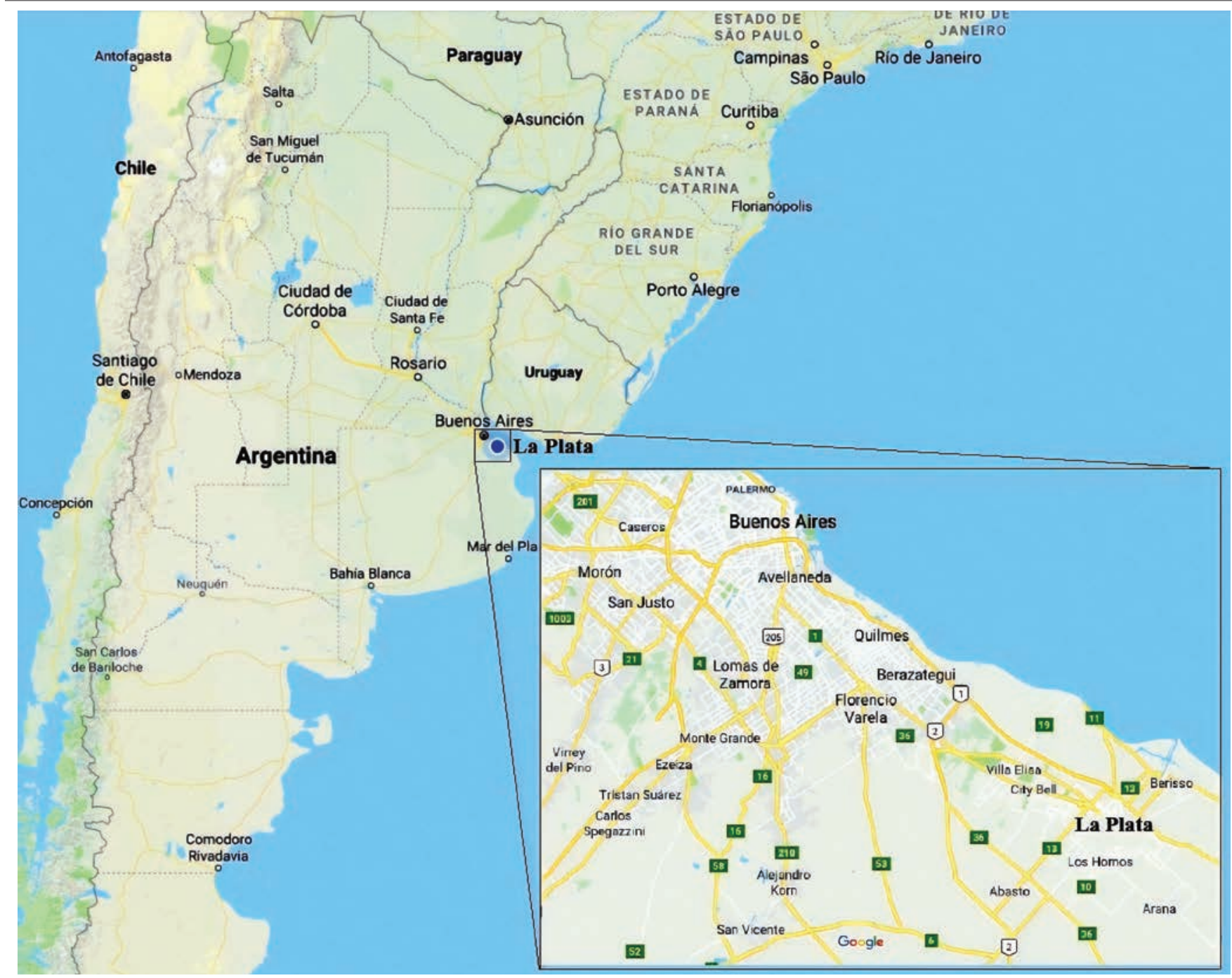

Fuente: Elaboración propia a partir de las capturas de Google Maps.

fin y cabecera del partido homónimo. Se encuentra ubicada a unos $56 \mathrm{~km}$ en dirección sudeste desde la Ciudad Autónoma de
Buenos Aires, formando casi el extremo del corredor sur(este) de la Región Metropolitana de Buenos Aires (RAMBA) (figura 1). territarias 39 
Según datos de Instituto Nacional de Estadísticas y Censos (INDEC), para el censo de 2010 contaba con una población de 654324 habitantes, de los cuales $51,82 \%$ fueron asignados como mujeres y el $48,18 \%$ como hombres. Actualmente, se estima su población en unos 753378 habitantes y su aglomerado urbano, el Gran La Plata, que incluye los partidos de Berisso y Ensenada, cuenta con unos 899523 habitantes. Es así la cuarta ciudad más poblada del país, y el quinto conglomerado urbano

Figura 2. Imagen satelital del casco fundacional de La Plata, alrededores y principales vías de acceso terrestre

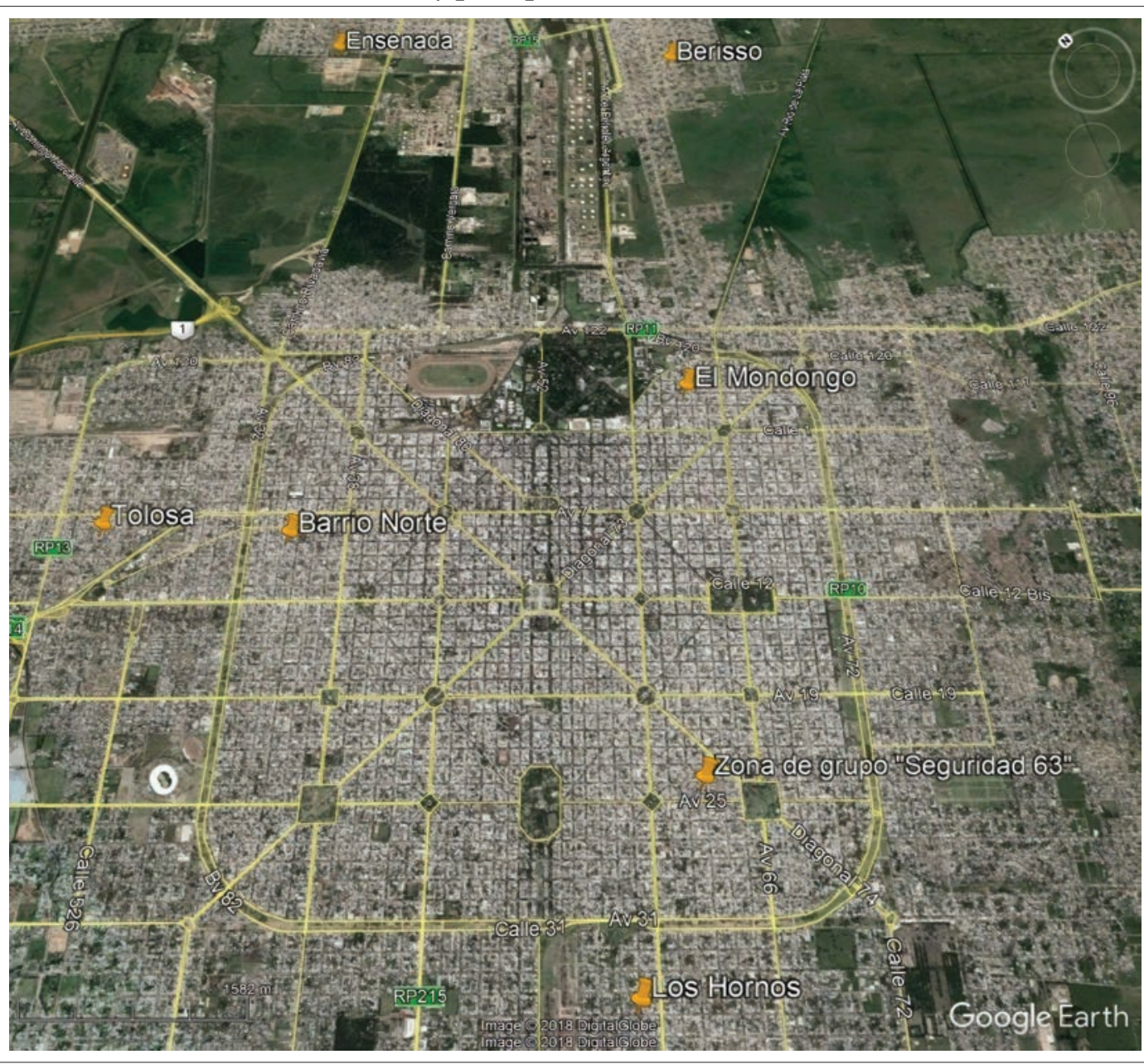


más grande, detrás de Buenos Aires, Rosario, Córdoba y Mendoza. Para entonces, se relevaron 221313 hogares, con una población urbana del $98 \%$ y un $2 \%$ de población rural. Según el INDEC, para el primer trimestre del 2017 hubo un 10,6\% de desocupación. Aproximadamente, la población universitaria total se estima en unos 130000 estudiantes. El promedio de personas por vivienda es de 3,06.

La disposición del casco urbano de La Plata tiene un singular trazado por ser una de las pocas ciudades que contó con un diseño y planificación previa a su fundación (figura 2). Esta empresa estuvo a cargo de las élites políticas de fines del siglo XIX que se inspiraron en el higienismo urbano, $\mathrm{co}^{-}$ mo los boulevards del barón de Haussman para París o el Ringstrasse de Viena. Las amplias avenidas, las diagonales que la surcan y permiten la circulación del aire, no solo tenían fines de salud pública sino también la evasión de pequeñas calles en lugares centrales para el poder político, que en la capital francesa habían posibilitado la formación de barricadas y movimientos insurgentes, como la Comuna de París.

En el folleto de propaganda de una política pública municipal (figura 3 ) que circuló en las calles y fue recolectado en los primeros días de julio de 2017, se puede encontrar la persistencia de la forma que asocia simbólicamente la ciudad actual con aquel plano fundacional (Segura, 2015). Concurrentemente, se encuentra la presencia de mensajes e imágenes asociadas con el tema securitario, esta vez superpuestas a una idea de futuro, como una especie de metáfora tecnológica.

La política está específicamente orientada hacia el casco urbano - donde se recolectó el folleto- reforzando la gran postergación en políticas de todo tipo que sufre el afuera del cuadrado, donde todos los indicadores de Necesidades Básicas Insatisfechas son mayores (Segura, 2015). En la construcción de estas imágenes, además del cuadrado, son pregnantes la figura de la familia tipo, la presencia estatal/policial y los espacios verdes o abiertos que son además los lugares a los que serán destinados los respectivos "Nuevos centros de monitoreo barrial". No es menor señalar que esta política se da en un contexto previo a elecciones legislativas y ya fue señalado el peso que tienen estas temáticas: el anuncio se produjo hacia mediados de julio y en septiembre habían comenzado a construir varios de los puestos proyectados; a su vez estos once centros de monitoreo se combinaron con unas 85 cámaras de videovigilancia. Esta propuesta de "modernización" se combina - entre otras propuestas - con instalaciones de luminarias, mejoramientos de corredores peatonales en boulevards y avenidas.

Otros ejemplos de este lenguaje securitario en políticas electorales se encuentran en los representantes del partido "1País", con la propuesta de Sergio Massa y Margarita Stolbizer de instalar 12000 alarmas vecinales en la provincia de Buenos Aires como parte de su campaña (Veneranda, 2017). Es también en la figura de Massa 


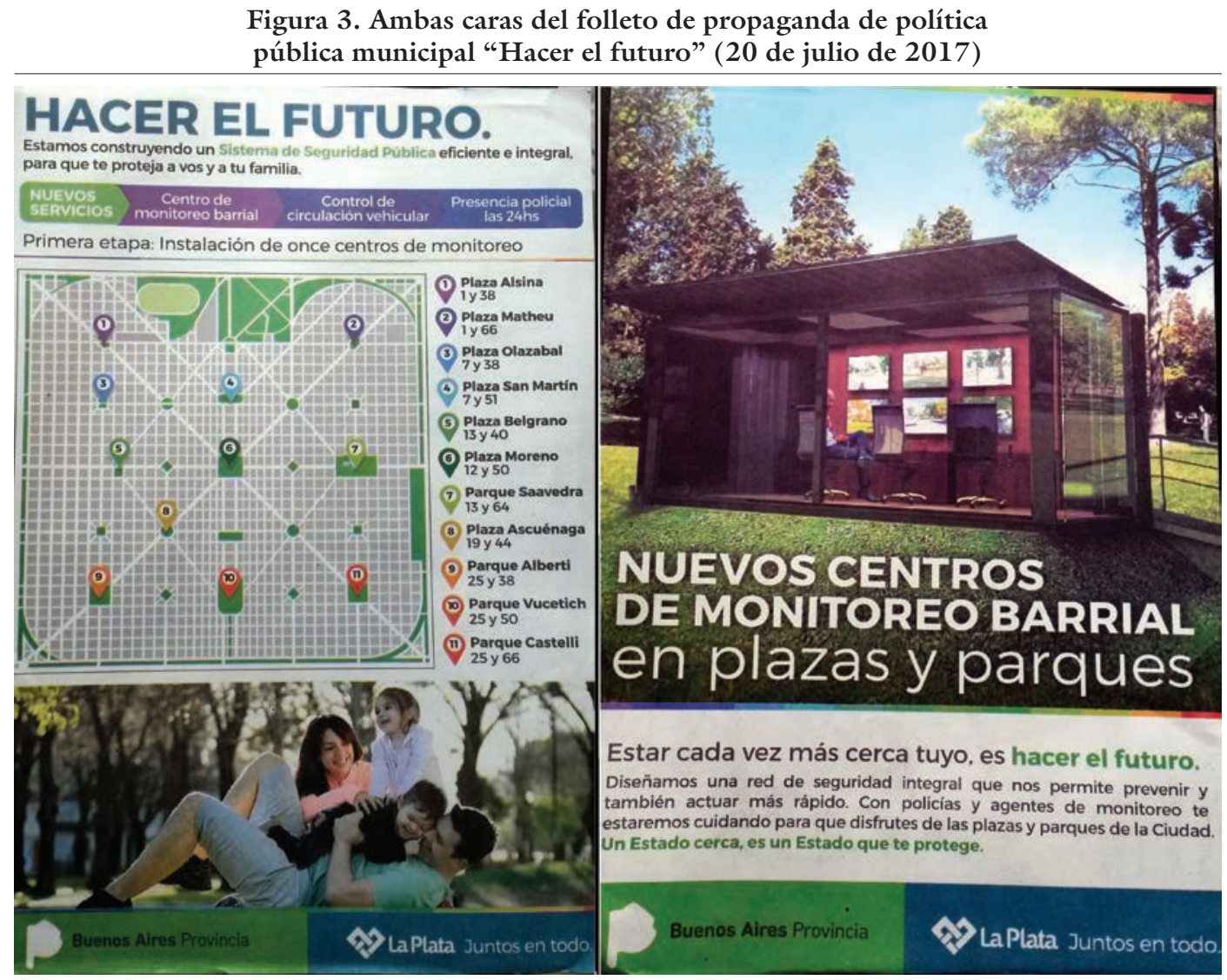

Fuente: Folleto "Hacer el futuro. Nuevos centros de monitoreo barrial en plazas y parques” en la vía pública.

donde queda más clara la asociación inseguridad/narcotráfico/intervención militar, que, de todos modos, ya constituye el mensaje oficial de las imágenes que hace circular el Ministerio de Seguridad de la Nación en su canal de YouTube (Ministerio de Seguridad de la Nación, 2017), que actualmente desarrolla un dispositivo denominado "Barrios Seguros" (https:// youtu.be/nEvhPXbFMsk). Unos días después, José Arteaga del Frente Renovador anunció el lanzamiento del sistema "Alerta Buenos Aires”, una app (aplicación móvil) con la que se pueden hacer denuncias al 911 (Radio Provincia, 2017). En el mes de julio, la gobernadora de Buenos $\mathrm{Ai}^{-}$ res, María Eugenia Vidal, lanzó la app "Seguridad Provincia" que permite hacer denuncias, similar a las impulsadas por el Frente Renovador en el Partido de Tigre, por lo que participantes de este sector político manifestaron con agrado que el 
PRO / Cambiemos se inspire en las políticas securitarias que llevan adelante $(\mathrm{La}$ Política Online, 2017). Por otro lado, en Los Hornos, adyacente a la zona suroeste del cuadrado, crearon una aplicación para celulares llamada "Alerta La Plata", impulsada por Emmanuel Polo y la asamblea contra la inseguridad de Los Hornos. Un mismo suelo cultural permea buena parte de estos gestos de securización.

En La Plata existen diversas asambleas nucleadas en torno al problema securitario. Algunas de ellas preexistían o tuvieron como capital organizativo previo las asambleas de inundados que se produjeron luego de una gran inundación en abril del 2013, donde más de 100 personas perdieron su vida ${ }^{7}$ y miles se vieron severamente afectadas con alturas de hasta 2 metros de agua y barro dentro de sus casas. En relación con su actualización, con respecto al problema securitario, que exista esta preocupación y proactividad marca una relativa no-naturalización de este escenario ante un Estado que no puede gestionar un umbral tolerable de riesgos para la vida urbana: las tasas de victimización en las principales ciudades son altas, cercanas a un $30 \%$ de personas que dicen haber sido víctimas de algún delito en el último año o en los últimos seis meses según las encuestas (Kessler, 2011). De todas maneras, las respuestas y demandas más comunes por estos grupos, que logran hacerse un lugar en la agenda pública y la visibilidad mediática, suelen ser de mayor presencia policial, la instalación de dispositivos tecnológicos de empresas de seguridad o la contratación de seguridad privada (donde es frecuente la presencia de policías retirados/as). A la vez, otra solución intermedia entre lo público y privado, es el pago de una "comisión" a las comisarías de la zona, donde los/as policías fuera de sus horas de trabajo hacen sus "horas extras" con diferentes cánones según se trate de la provincial o federal (esta última con mayor prestigio). En algunos casos de poblaciones vulneradas, la presencia de la gendarmería es bien vista por no contar con los "vicios" de la policía para el control de los territorios, aunque en el caso de La Plata no ha habido en los últimos tiempos intervenciones directas de gendarmería - a excepción del caso de las inundaciones mencionadas - como sí ha sido más frecuente en otras zonas del conurbano bonaerense.

\section{Liga de barrios por la seguridad de La Plata}

Volviendo sobre uno de los incipientes procesos de institucionalización que se mapean y se siguen para esta investigación, se menciona brevemente de la "Liga de los barrios platenses por la Seguridad" que se formó en el primer cuatrimestre del 2017. Su creación es producto de la confluencia de diferentes asambleas y núcleos de vecinos y vecinas movilizados por "el problema de la seguridad". Bajo este acápite, que se espera poder mantener como un significante abierto y performativo, se conjugan principalmente robos y delitos contra la propiedad que en ocasiones se asocian con daños contra las personas (heridas,
Según la investigación coordinada por el Juez en lo Contencioso y Administrativo, Luis Federico Arias, los registros oficiales fueron falsificados para adulterar los números, práctica que también estaba sedimentada en los modus operandi de la policía y la morgue policial cuando necesita borrar las huellas de su accionar (Rodriguez, 2016).

territarias 39

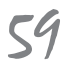


${ }^{8}$ La denominación nativa de local se conservará, pero es importante señalar que al crearse este cuerpo de fuerzas de seguridad durante el último gobierno de Daniel Scioli en la provincia de Buenos Aires (2011-2015), laspujascon las intendencias - principalmente del conurbanolas dispuso como parte del organigrama del Ministerio de Seguridad de la provincia de Buenos Aires por lo que responden a la misma dirección que "la bonaerense", como se conoce en términos nativos a la policía provincial.

${ }^{9}$ En algunos casos, incluso en relación con la intervención multiagencialque incluye presencia de Gendarmería y Prefectura en los territorios, como en los operativos Cinturón Sur y Escudo Norte.

${ }^{10}$ Esto suele abarcar el espacio de una "cuadra" o "manzana" aunque a veces el diseño, como en un caso de Berisso, la disposición es en " $H$ " tomando dos medias manzanas.

${ }^{11}$ En muchos casos de barrios populares, la organización diaria del grupo familiar o doméstico gira en torno a la necesidad de asegurar que siempre haya alguna persona en la vivienda, de manera que no

territarias 39 homicidios, abusos) pero también incluyen al trabajo sexual, narcotráfico y situaciones traumáticas de diversa índole. La mayoría de los barrios representados pertenecen al casco fundacional. Bajo estas reuniones, el interés está en poder articular con diferentes agencias del Estado (Policía local ${ }^{8}$, provincial, federal ${ }^{9}$, municipios, Gobernación provincial), a la vez que organizarse entre los y las participantes para decisiones en torno al control, regulación y redes del espacio urbano habitado.

Esta articulación ha posibilitado una mayor visibilidad y presencia en la prensa - particularmente en los diarios El Día y $H o y$, que son los que cuentan con mayor tirada diaria - aunque las principales acciones se han orientado a coordinar y sostener encuentros mensuales que no alcanzan una periodicidad persistente. De todas formas, algunas de las diferentes asambleas continúan con reuniones más periódicas $\mathrm{y}$ al menos en términos del imaginario, el espacio existe como referencia, y como capital organizacional en caso de necesitar ser movilizado o actualizado.

Muchas de las decisiones que toman sus participantes (y no solo ellos/as), individual o colectivamente, son la instalación de rejas, inscripciones sobre las viviendas, carteles de alarmas, instalación de cámaras - en muchos casos falsas o no monitoreadas-, pinchos, alambres de púas, contratación de seguridad privada o pago de servicios a las comisarías para protección, que suelen ser parte del repertorio de acciones. Aquellas que se traducen en cambios materiales y arquitectónicos se van sedimentando y acumulando en el espacio urbano. Otra de las soluciones más difundidas es la instalación de alarmas/ luces controladas por quienes habitan un sector delimitado y específico ${ }^{10}$.

Por el momento, cabe decir que las formas asamblearias o de organización vecinal de este tipo no han proliferado en estas modalidades ni en sectores de barrios privados (donde la tercerización de la seguridad es uno de los servicios codiciados por quienes pueden acceder a ella) ni por sectores de barrios más postergados (donde muchas veces la desconfianza prima hacia el interior de la zona habitada sin que el peligro esté depositado en un otro exterior a construir ${ }^{11}$ ) al menos en los lugares y medios registrados hasta ahora en el ámbito platense. Sin embargo, en muchos espacios urbanos también se desarrollan otras formas menos institucionalizadas. A continuación, se relata parte de la experiencia de trabajo de campo etnográfico en curso en un contexto de asociación no institucionalizada.

\section{4. ¿Riña de gallos? Devenires y accesos al campo}

Mis primeras notas de campo fueron robadas junto con una mochila, una noche a fines de diciembre del $2016^{12}$. Era aproximadamente la una de la mañana del sábado y, acompañado por Paula ${ }^{13}$, de 27 años, habíamos descendido de un auto que nos dejó a unos cien metros de su casa; en la mitad de dicho tramo fuimos interceptados por dos personas en una motocicleta 
de alta cilindrada que se aproximaba en el sentido contrario de circulación por la vereda (andén), mientras observábamos sorprendidos cómo desde varios metros antes nos apuntaban con una pistola semiautomática que parecía una $9 \mathrm{~mm}$. En la calle vacía de transeúntes, con árboles de paraíso, poco iluminada y con autos estacionados a ambos lados de la calle, una zona de clase media residencial de pocos edificios y algunas casas con ladrillo a la vista, nos acorralaron entre la moto y la pared mientras nos amenazaban para que les diéramos nuestras pertenencias (cartera y mochila). El hecho de tener sus cascos puestos nos imposibilitaba ver sus rostros. Cuando pedí tomar mis apuntes y alguna libreta, quien nos apuntaba abajo de la moto me dio un golpe en la cabeza con su arma para que desistiera y automáticamente se llevaron ambas pertenencias mientras aceleraban con un sonido que quedó varios días en mi cabeza. En la esquina de la calle, también detuvieron a un hombre de unos 35 años para pedirle el teléfono celular que llevaba en su mano y salieron otra vez, raudamente.

El momento fue bastante chocante por la rapidez de toda la situación. Por suerte nos encontrábamos bien más allá del susto y el golpe no me hizo más que una hinchazón y un pequeño corte que casi no sangró. Con la adrenalina de la situación e intentando salir de la temporalidad del acontecimiento disruptivo, pedimos ayuda en la casa que se encontraba próxima al lugar del robo. Aunque era posible ver y escuchar que había personas dentro, nadie salió. Sin llaves ni teléfono (el teléfono y llaves de Paula se encontraban en su cartera mientras que mi celular estaba en mi bolsillo y no me lo robaron pero estaba sin batería) nos acercamos entonces hacia la casa de Paula, ubicada a unos 60 metros del lugar del robo.

El vecino contiguo a su casa, Toto, salió inmediatamente cuando golpeamos su ventana; luego salieron su mujer, Miriam, y su hija menor, Micaela. Por fin nos sentíamos acompañados/as. Él llamó inmediatamente a la policía. Fue una suerte que llegara enseguida el hermano de Paula, Marcos, junto a una amiga que estaba de visita en la ciudad, por lo que pudimos entrar a la casa con sus llaves. Yo salí corriendo por las calles a través de las cuales se habían dado a la fuga quienes nos asaltaron, en la búsqueda de que descartaran documentos, libros y otros objetos personales. Pero después de unas vueltas sin encontrar indicio alguno, volví para la casa de Paula. Allí ya estaba un patrullero policial, nos subimos a su vehículo con Toto (en pijamas y descalzo). Nos encontramos con otro patrullero a unos doscientos metros y en la conversación una de las policías se quejaba de los robos, afirmando "hay que matarlos a todos", ante lo cual la interrumpí cortante, todavía un poco alterado por la situación previa, manifestándole mi desacuerdo y alarma de escuchar su afirmación punitivista.

Sin seguir demasiado la conversación, continuamos circulando en las patrullas en un radio de menos de 3 cuadras, lo que me pareció algo sospechoso, como si quede "sola" y sea objeto de hurtos o entraderas.

12 En la escritura de estas secciones se incorporará parte de las notas de campo en un formato de crónica, intentando mantener el tono del registro etnográfico en busca no tanto de reforzar la autoridad del haber estado alli, como de señalar las emociones, experiencias $y$ formas de transitar los acontecimientos relatados.

${ }^{13}$ Los nombres reales de las personas, apodos de mensajería instantánea, números de teléfonos celulares, números de calles y del grupo han sido modificados para no facilitar su identificación, aunque se conservarán los de las asambleas ya instituidas que han buscado tener visibilidad en los medios y el de las empresas de seguridad.

territarias 39

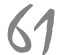


${ }^{14}$ El hecho de que fuese cercano a las fiestas de Navidad y Año Nuevo sugiere la duda sobre estrategias que tiene la policia a partir de la regulación de delito como forma de negociación politica (Rodriguez, 2014).

${ }_{15}$ Abreviatura de propiedad horizontal. Se utiliza comúnmente para nombrar una cantidad de viviendas o departamentos en edificios que en general no tienen más de dos plantas en altura y que comparten un pasillo interno para acceder. Generalmente, son producto de remodelaciones de casas más grandes que se han subdividido, o antiguos patios internos sobre los que se ha edificado.

${ }^{16}$ Esta modalidad es repetida en diversos lugares de la ciudad entre personas que viven en un mismo edificio o zona de la ciudad.

\section{territarias 39}

las personas se fuesen a quedar cerca de allí pasados unos 20 minutos, en la calle, esperando que los encuentren. Más tarde me enteraría de más robos ocurridos esa noche, algunos ocurridos a unos cien metros de la casa en la que vivía, por lo que no dejé de sospechar de una "noche liberada" en las que la policía da su venia a ciertas personas que suelen reclutar para que incursionen en delitos mientras se siembra el pánico moral (Saín, 2017). ${ }^{14}$

Mientras volvíamos caminando, Toto relataba otras ocasiones en las que habían sido robados/as; que habían entrado en su casa pero que por suerte a él y a su familia nunca los habían lastimado, solo llevado pertenencias y algo de dinero, con el cual nunca contaba en abundancia. Él trabaja de mecánico y luego de la inundación de abril del 2013 perdió casi todo en Tolosa, mudándose al actual $\mathrm{PH}^{15}$ en el que vive. Trabaja en la calle por no tener taller ni lugar donde guardar los autos que tiene que arreglar. Así, me comentó que una noche incluso encontró que estaban intentando robarle unos neumáticos de uno de los autos fuera de su casa, a lo que resultó que quien lo estaba haciendo trabajaba de policía.

Un mes después, a fines de enero, la puerta de entrada de la casa de Paula quedó mal cerrada y entraron durante la noche, pero solo atinaron a llevarse su notebook que había quedado sobre la mesa y muy cerca de la puerta de entrada. Como dicha puerta estaba abierta, Toto llamó a la policía y llegaron rápidamente dos oficiales. Paula también perdió mucha de su información y trabajos que no tenía subidos a "la nube". Estas situaciones, entre otras, detonaron la creación de un grupo de WhatsApp, "Seguridad 63" (en alusión a la calle), en el que fuimos incluidos/as y donde se empezaron a coordinar posibles reuniones.

\subsection{Notas sobre el grupo de WhatsApp}

Una de las formas que encontró este grupo de vecinos/as para hacer frente a la cuestión de la seguridad, fue la creación de un grupo de mensajería instantánea a fines de $2016^{16}$. A este grupo de WhatsApp fui añadido por Toto el 30 de enero de 2017. El 5 de Febrero, después de una tormenta con fuertes vientos, una de las conversaciones refirió a la falta de señal de cable, remarcando algunos/as la imprudencia de quienes cortaron ramas caídas sin permiso municipal. Unos días más tardes se produjo una falta de suministro de agua corriente en varias zonas de la ciudad, y esta zona se quedó sin este servicio, por lo que se preguntaba en el grupo quiénes tenían agua y se establecían acuerdos de forma de que aquellos/as que tuviesen cortado el servicio pudieran coordinar para cargar bidones. Esto hizo que diera mayor atención a los variados asuntos que eran considerados dentro de un marco de acción dado por las inseguridades (Varela, 2005; Rodríguez, 2016).

Luego de unos días, Toto comentó que habían querido entrar a su casa durante la noche, y que había hablado con 
el comisario para que pasasen más asiduamente. Aclaraba también la necesidad de "dejar todo serrado porque no hay luz de mercurio" 17 . Luego, comenzaron a hablar de una "colaboración" entre vecinas y vecinos, en pos de juntar dinero para que la policía efectivamente pasase con mayor frecuencia; también se concertó una reunión para evaluar la posibilidad de poner dos cámaras de videovigilancia, pero que no tuvo mucho éxito ya que se concretó con pocas personas. Finalmente, no se resolvió continuar con ninguna de las estrategias que se esbozaron (carteles, cámaras, seguridad privada / arreglo con la policía) pero sí se entablaron lazos con la comisaría y el nuevo comisario que asumió a principios del 2017, ya que el anterior había sido despedido, asociado, junto con otros comisarios de la ciudad, con un caso de corrupción y sobornos dentro de la fuerza ${ }^{18}$.

En la esquina de la cuadra, a unos 15 metros de la casa de Paula, hay un almacén que fue robado varias veces durante los meses anteriores a la creación del grupo de mensajería. Una de las últimas ocasiones en que tuvo lugar el hecho delictivo, llamó en parte la atención de los vecinos/as no se hubiesen enterado por los almaceneros, y se manifestó la no conformidad de estos en relación con instalar cámaras o contratar alguien que vigile. Allí también tomé conocimiento de que hay presupuestos que varían según se contraten servicios de la comisaría del barrio (provincial), de la policía federal o un servicio privado. El hecho es que todos/as los/as vecinos/as tenían que poner dinero mensualmente y esto dificultó que las personas accedieran; la no participación del comercio generó algunas distancias (uno de los almaceneros se fue a trabajar a un comercio de otra zona de la ciudad). Esto nos sirve de indicio para considerar que la seguridad y las tomas de decisión respecto del espacio habitado en este asunto no siempre unen a los/as vecinos/as y comerciantes, lo que evidencia lo contingentes y heterogéneos que pueden resultar estos ensamblajes (Latour, 2013).

Las siguientes conversaciones que tuvieron lugar en el grupo fueron sobre cortes de luz y cable. Un tiempo después, circuló una imagen para la búsqueda de una joven, una modalidad que se hizo más común en los últimos dos años en el uso de los grupos de WhatsApp en La Plata, mostrándonos algunos indicios sobre las formas diferenciadas en las que se transita el miedo y la inseguridad según el sexo o género y la edad. Media hora después avisaban que la chica ya había aparecido en buenas condiciones y no circuló mayor información sobre ella.

Unos 20 días más tarde, una vecina se refirió a la presencia de "dos hombres bien vestidos medio sospechosos en la puerta y el portón como queriendo abrir y que hasta sacaron una foto de la casa". Toto afirmó: "donde vea algo raro llamo a la policía". Otro vecino preguntó por qué la vecina que los vio no llamó al 911 (línea telefónica para emergencias y denuncias), a lo que contestaron que habían pensado que eran de una inmobiliaria porque estaban "bien vestidos", lo que muestra algunos
${ }^{17}$ Se mantendrá la ortografía original de los mensajes, como los errores de tipeos para mantener inscripciones propias de la materialidad del registro que en ocasiones potencian el ruido y las ambigüedades de los mensajes.

${ }^{18}$ Referimos a la llamada "causa de los sobres" que tuvo un gran impacto mediático y hasta el momento se encuentra en vias de sustanciarse judicialmente.

territarias 39

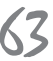


${ }^{19}$ Estas temáticas han sido particularmente evidenciadas en los estudios anglosajones sobre white collar crimes y la falta de visibilidad de los delitos cometidos por sectores de clases medias y altas, manteniendo los sesgos clasistas, racistas y etarios de la cuestión punitiva (Rodriguez, 2014).

\section{territarios 39}

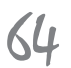

de los estereotipos esperados para quienes cometen estos delitos, más a asociados con varones jóvenes de sectores populares, y ciertas "sorpresas" cuando esas figuras resultan poco adecuadas para interpretar desviaciones respecto de este constructo sedimentado. ${ }^{19}$

En la siguiente conversación, Miriam narraba que les habían robado cosas de adentro del auto que por las noches suelen estacionar afuera de su casa, y pedía que, como no se iban a encontrar en su casa hasta más tarde, intentaran mirarla durante el día.

Vamos delineando algunas de las formas en que se organiza y se emplean las redes entre los vecinos/as que participan de la gestión de la seguridad y vemos esbozadas algunas formas de cuidados mutuos, ya que el canal de comunicación opera para prevenir o alertar vecinos/as de actividades sospechosas y compartir estrategias de resolución (llamar al 911, llamar a la policía, "estar atentos todos"). La relativa ubicuidad que se produce con el uso de teléfonos celulares para poder compartir en tiempo real información sobre el espacio habitado, hace que esta red de datos permita que las visibilidades de sus participantes encuentren un lugar de traducción y puesta en común, donde hacen foco en una forma de control emergente.

Un hecho que me resultó llamativo fue que en los siguientes días, Toto (quien creó y administra el grupo, resultando ser uno de sus miembros más activos) y su familia, compartieron que estaban organizándose para realizar una comida caliente los viernes a la noche y repartirla entre personas en situación de calle, por lo que el medio sirvió para coordinar aportes y préstamos de vecinos/as para esta tarea. Esto se continuó durante varios días, mostrando algunas derivas impensadas del grupo "securitario", que se articulaba con un devenir cercano a la ayuda, el altruismo y lo humanitario.

Figura 4. Capturas de pantalla del grupo de WhatsApp Seguridad 63

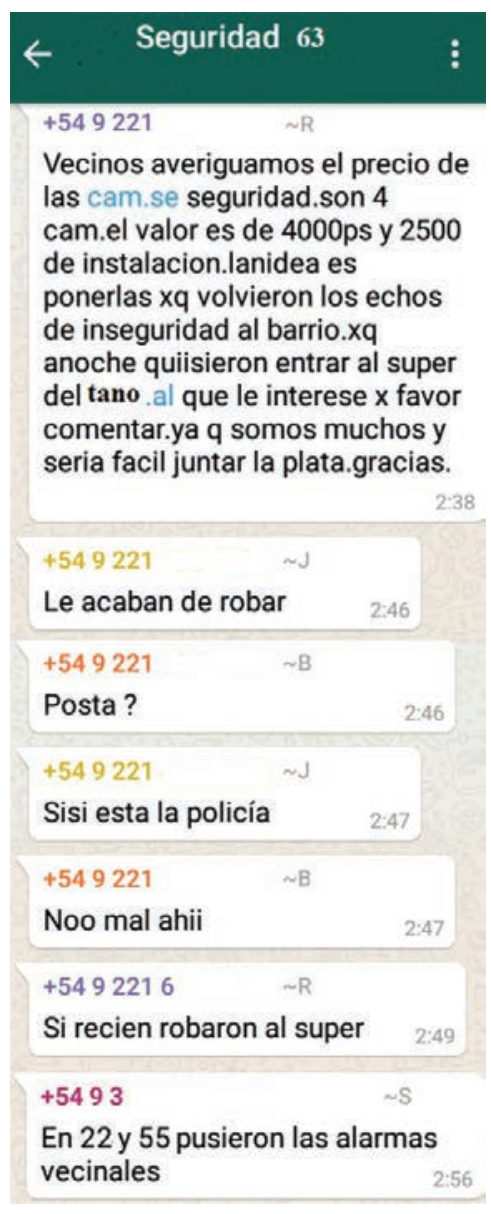


Seguidamente, la conversación registrada (figura 4) versó sobre la posible instalación de cuatro cámaras sobre las que Toto había oportunamente averiguado. Estas tenían un valor de 4000 y 2500 pesos argentinos de instalación, y la premura de llevar la medida adelante había sido desencadenada en relación con que la noche anterior a dicha conversación, habían querido "entrar al super del Tano" y habían vuelto "los echos [sic] de inseguridad al barrio", proponiendo que al ser muchos/ as sería fácil “juntar la plata”, en referencia al dinero necesario.

Inusitadamente, la respuesta fue que en ese mismo momento en el que intercambiaban los mensajes, acababan efectivamente de robar el almacén y ya estaba la policía en el lugar. Así, podemos evidenciar otra de las formas en las que opera esta inmediatez de la comunicación y las diferentes temporalidades que se superponen (toma de decisiones sobre instalación de cámaras / acontecimiento inmediato del robo) en la articulación de la mensajería con estos suelos securitarios y diferentes formas culturales del control (Garland, 2005; Melossi, 2001; Caldeira, 2007).

Hubo más tarde ciertos comentarios de vecinos/as acerca de que el robo estaba relacionado con la negativa del Tano de aportar una "comisión" a la comisaría, por lo que habría sido una manera de presionarlo para que aceptara ese arreglo, aunque no pude confirmar esta versión con él. De todas formas, esto muestra cierta desconfianza y ambivalencia existente en relación con la institución policial, como una de las caras territorialmente visibles de las agencias estatales.

Unos días más tarde, en el grupo comentaban (figura 5) que vecinos/as de otro sector del barrio habían recientemente instalado alarmas vecinales por la empresa "Maniatec" con un costo de 12000 pesos

Figura 5. Capturas de pantalla del grupo de WhatsApp Seguridad 63

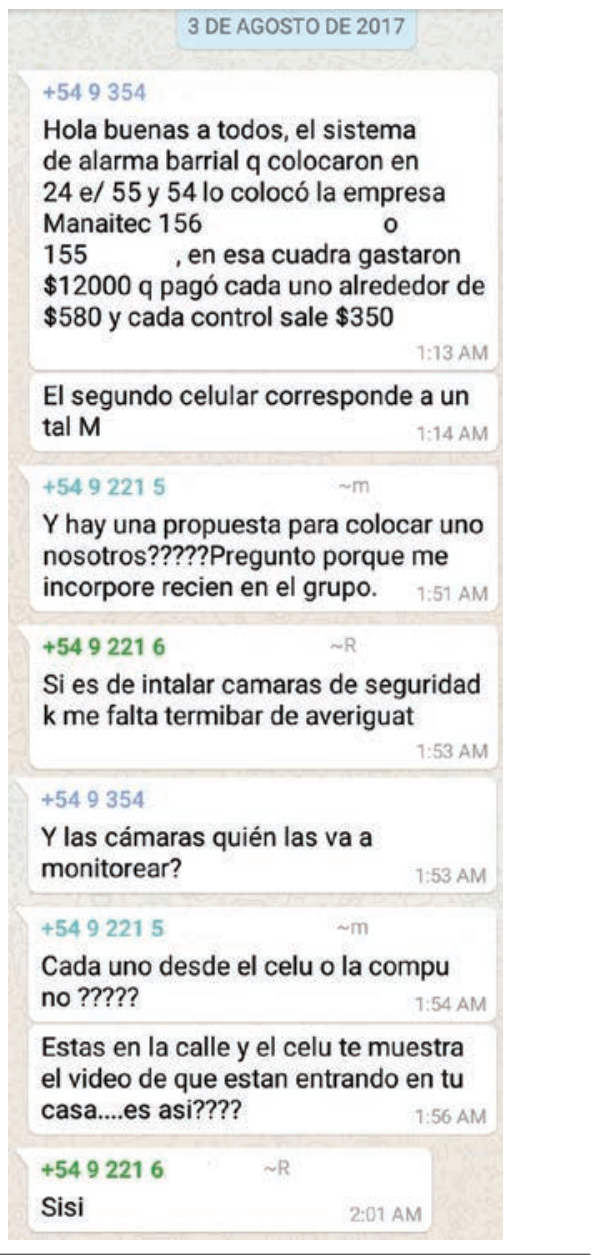

territarias 39 
argentinos (en ese momento, equivalente a 800 dólares) con los posibles números de teléfono de contacto. A su vez, las cámaras que se proponían instalar podrían ser monitoreadas desde los teléfonos celulares de las personas vecinas o bien desde un sitio en Internet.

Sin embargo, pasados algunos meses de esta propuesta, todavía no se habían concretado acciones en relación con la instalación de nuevos dispositivos. El grupo continúa en actividad y las conversaciones más comunes siguen refiriéndose a problemas en los servicios de agua, luz, televisión por cable o a mascotas perdidas.

\section{Epílogo}

En estos movimientos se intenta introducir el problema de la (in)seguridad, tanto en un marco más general en América Latina y sus desarrollos conceptuales, como en el trabajo etnográfico en esta acotada zona de La Plata y la manera en que se adoptan disposiciones y estrategias para ejercer algún control sobre el espacio habitado, construyendo ensamblajes que refuerzan o disputan formas de gubernamentalidad. Aunque el Estado aparece en las políticas públicas y propagandas, o en su faceta del poder de policía, es muy relevante el papel que cumplen las empresas privadas que brindan los servicios, como también las iniciativas de las personas que habitan el territorio para gestionar su propia seguridad.

A la vez, se observan grandes dificultades para coordinar acciones por los medios virtuales como la aplicación de
WhatsApp y mensajería instantánea, ya que la responsabilidad que asumen los actores no tiene el factor de interpelación que tal vez adquiriría una asamblea presencial, como sí se están llevando adelante en otras zonas como en el Barrio Norte, Tolosa o El Mondongo, pero sobre las que todavía no he realizado un trabajo de campo presencial. Cabe resaltar en estos casos, que un capital organizativo previo provenía de asambleas vecinales en torno a la inundación de 2013 o bien en torno a clubes de barrio consagrados como lugares de encuentro, que han sido recurrentemente utilizados para las reuniones de las asambleas y para la "Liga...", mientras que la creación suigeneris con base en medios virtuales no termina siendo por el momento tan eficiente para llevar adelante acciones sin una dinámica y confianza previamente sedimentada (aunque sí a fin de comunicar eventos ocurridos), al menos en el caso mapeado en profundidad. Allí donde el disparador fue un acontecimiento disruptivo - como es el caso de la asamblea del barrio El Mondongo, cuyo surgimiento se vio motivado por el homicidio de un vecino- la toma de decisiones y ensamblajes sí se produjeron con mayor prontitud y resolución. De todas maneras, también constituye un desafío y reflexión pendiente en relación con cómo llevar adelante estos trabajos de campo multisituados que incorporen la participación de ámbitos virtuales como los de la mensajería instantánea, tan extendidos en los últimos años.

Por otro lado, también se evidencia en un pequeño gesto algunas dificultades del 
trabajo de campo en este contexto, como la posición incómoda y paradojal de quien investiga, incapaz de recurrir a discursos y moralidades prefabricadas tanto para comprender como para actuar en estos casos en los que uno/a mismo/a es objeto de algún hecho delictivo disruptivo, sin capacidades alternativas para la resolución de conflictos. Esto está ejemplificado durante el acontecimiento del robo, en la necesidad de recurrir a una institución policial que tal vez fuese la misma que habilitó la liberación de ciertas zonas para la comisión de estos, como en el robo del almacén. A su vez muestra la distancia entre los datos de las estadísticas - la poca proporción de robos en Argentina que terminan en una muerte- con el hecho de haber tenido la experiencia de ser apuntado o amenazado con un arma de fuego, quizá especialmente cuando se trata de la primera experiencia, como fue en nuestro caso. Esto aporta un señalamiento para poder rastrear en futuros trabajos los relatos y narraciones sobre las experiencias de victimización y cómo eso produce modificaciones en el estar en la ciudad, ${ }^{20}$ aspectos que no son profundamente sopesados en estudios cuantitativos y encuestas de victimización, formando parte de este gravitar de los anclajes culturales que conforman estos suelos securitarios.

También queda por ahondar la masculinización del paradigma securitario, como la relativa inseguridad de los cuerpos de las mujeres jóvenes que han sido reiteradamente objeto de secuestros y desapariciones, de lo cual la foto que circuló en el grupo de mensajería fue un pequeño ejemplo. Quedan pendientes las futuras derivas a mapear de las asambleas y la "Liga..." como también las políticas que está llevando adelante el gobierno del Partido "Cambiemos" que dirige el estamento municipal, provincial y estatal y las articulaciones con las empresas de seguridad privada. Aunque sea alimentar una esperanza, que a veces deviene una pasión triste, queda en el fondo y entrelíneas la apuesta de que estos movimientos y giros nos permitan comprender un presente lleno de dificultades, en pos de un mundo donde quepan bienestares para todos y todas.

\section{Referencias}

Caldeira T. (2007). Ciudad de Muros. Barcelona: Gedisa.

De Certeau, M. (2000). La invención de lo cotidiano I. México: ITESO.

Deleuze, G. (2005). Derrames. Entre el capitalismo y la esquizofrenia. Serie Clases. Buenos Aires: Editorial Cactus.

Douglas, M. (1994). Risk and blame. Essays in cultural Theory. Londres: Routledge.

Frederic, S. (2004). Buenos vecinos, malos politicos. Moralidad y politica en el Gran Buenos Aires. Buenos Aires: Prometeo.

Font, E. (1999). Transformaciones en el gobierno de la seguridad: análisis exploratorio de conceptos y tendencias. Su relevancia en Argentina. En M. Sozzo (Ed.). Seguridad Urbana. Nuevos problemas, nuevas perspectivas (pp. 89118). Santa Fe: UNL.
${ }^{20}$ Los dias posteriores a este robo, compartiamos con Paula la sensación de que los ruidos similares al de la motocicleta nos remitían a cierto temor y miedo, especialmente en lugares en los que estábamos solos/as o de noche.

tersitarios 39

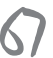


Foucault, M. (2007). Seguridad territorio y población. Buenos Aires: FCE.

Garland, D. (2005). La cultura del control. Crimen y orden social en la sociedad contemporánea. Buenos Aires: Gedisa.

Gorelik, E. (2008a). El romance del espacio público, Alteridades, 18(36) 33-45.

Gorelik, E. (2008b) La aldea en la ciudad. Ecos de un debate antropológico. Revista del Museo de Antropología, 1, 7396.

Grimson, A. (2009). Introducción: clasificaciones espaciales y territorialización de la política en Buenos Aires. En A. Grimson, C. Ferraudi Curto \& R. Segura (Comps.). La vida política en los barrios populares de Buenos Aires (pp. 11-38). Buenos Aires: Prometeo.

Hannerz, U. (1986). La exploración de la ciudad. Hacia una antropologia urbana. Buenos Aires: FCE.

Kessler, G. (2006). Miedo al crimen: representaciones colectivas, comportamientos individuales y acciones públicas. Ponencia en Coloquio "Violencias, Culturas Institucionales y Sociabilidad", Flacso, Buenos Aires.

Kessler, G. (2009). El sentimiento de inseguridad. Sociología del temor al delito. Buenos Aires: Siglo XXI.

Kessler, G. (2011). La extensión del sentimiento de inseguridad en América Latina. Relatos, acciones y políticas en el caso argentino. Revista de Sociología e politica, 19(40), 103-114.

Kessler G. \& Merklen D. (2013). Una introducción cruzando el Atlántico. En

\section{territarias 39}

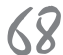

Murard. Individuación, precariedad, inseguridad. ¿Desinstitucionalización del presente? (pp. 9-21). Buenos Aires: Paidós.

Kusch, R. (2007). Geocultura del hombre americano. En Obras completas. Tomo III. Rosario: Editorial Fundación Ross. LaPolíticaOnline (12 de julio de 2017). Vidal presentó una app para denunciar delitos y D'Onofrio dijo que se alegra que les copien las ideas. LaPoliticaOnline. Recuperado de: http://www. lapoliticaonline.com/nota/106846vidal-presento-una-app-para-denunciardelitos-y-donofrio-dijo-que-se-alegraque-les-copien-las-ideas

Latour, B. (2008). Reensamblar lo social: Una introducción a la teoría del actorred. Buenos Aires: Manantial.

Latour, B. (2013). Investigación sobre los modos de existencia. Una antropología de los modernos. Buenos Aires: Paidós.

Lorenc V. F., Esteban, K., \& Guevara, T. (2012). El nuevo proletariado de la vigilancia: los agentes de seguridad privada en Argentina. Trabajo y sociedad, 19, 103-116.

Malinowski, B. (1986). Crimen y costumbre en la sociedad salvaje. Barcelona: Planeta-Agostini.

Marx, K. (1991). El capital. México D.F: Siglo XXI.

Melossi, D. (2001). The Cultural Embeddedness of Social Control: Reflections on the Comparison of Italian and North-Ameirican Cultures Concerning Punishment. Theoretical Criminology, $5,403-424$. 
Ministerio de Seguridad de la Nación (2017). Visitamos el barrio Carlos Gardel, Morón (Programa Barrios Seguros). Canal de Youtube (https://m.youtube. $\mathrm{com} /$ minseguridadar). Recuperado de https://youtu.be/nEvhPXbFMsk.

Monghin, O. (2006). La condición urbana. La ciudad a la hora de la mundialización. Buenos Aires: Paidós.

Radio Provincia (2017). En La Plata se lanzó la app "Alerta Buenos Aires" contra la inseguridad. Radio Provincia. Recuperado de https://www.gba.gob.ar/ radioprovincia/noticias/la_plata_se_ lanz\%C3\%B3_\%E2\%80\%9Calerta_buenos_aires\%E2\%80\%9D_contra_la_inseguridad

Reguillo, R. (1999). La construcción simbólica de la ciudad. Sociedad, desastre y comunicación. México: ITESO.

Reguillo, R. (2000). La construcción social del miedo. Narrativas y prácticas urbanas. En S. Rotker, (Ed.), Ciudadanias del miedo (pp. 185-202). Venezuela: Nueva Sociedad.

Rivera, C. S. (2014). Mito y desarrollo en Bolivia. El giro colonial del gobierno del MAS. La Paz: Piedra Rota/Plural.

Rodríguez, A. E. (2014). Temor y control: la gestión de la inseguridad como forma de gobierno. Buenos Aires: Futuro anterior.

Rodríguez, A. E. (2016). La máquina de la inseguridad. Buenos Aires: Estructura mental a las estrellas.

Rotker, S. (2000). Ciudades escritas por la violencia. (A modo de introducción). En S. Rotker, (Ed.), Ciudadanias del miedo (pp. 7-22). Caracas: Nueva Sociedad.

Saín, M. (2017) Por qué preferimos no ver la inseguridad (aunque digamos lo contrario). Bs. As.: Siglo XXI.

Segato, R. L. (2016). La guerra contra las mujeres. Madrid: Traficantes de sueños.

Segura, R. (2006). Territorios del miedo en el espacio urbano de la ciudad de La Plata: efectos y ambivalencias Question 1-14.

Segura, R. (2009). Paisajes del miedo en la ciudad. Miedo y ciudadanía en el espacio urbano de la ciudad de La Plata. Cuaderno Urbano, 8(8), 59-91.

Segura, R. (2015). Vivir afuera. Antropologia de la experiencia urbana. Buenos Aires: Unsam Edita.

Segura, R., \& Chaves, M. (2015). Introducción. Una antropología de prácticas juveniles en la ciudad. En M. Chaves \& R. Segura (eds.) Hacerse un lugar: circuitos y trayectorias juveniles en ámbitos urbanos. Buenos Aires: Biblos.

Sozzo, M. (2005). Policía, violencia, democracia: ensayos sociológicos. Santa Fe: UNL.

Sozzo, M. (2016). Postneoliberalismo y penalidad en América del Sur. [Libro digital]. Buenos Aires: FLACSO.

Shearing, C. (1995). Transforming the Culture of Policing: Thoughts from South Africa. Australian and New Zealand Journal of Criminology, 28, 54-61 (Special Supplementary Issue).

Tiscornia, S., Elbaum, L., \& Lekerman V. (2004). Detenciones por averiguación de identidad. Argumentos para la dis- territarias 39

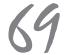


cusión sobre sus usos y abusos. En S. Tiscornia (Comp.) Burocracias y violencia. Estudios de antropología jurídica (pp. 125-158). Colección de Antropología Social; FFyL, UBA. Buenos Aires: Antropofagia.

Varela, C. (2005). ¿Qué significa estar seguro? De delitos, miedos e inseguridades entre los adultos mayores. Cuadernos de Antropología Social, 22, 153-171.
Veneranda, M. (21 de junio de 2017). Massa quiere instalar 12.000 alarmas barriales como parte de la campaña bonaerense. La Nación. Recuperado de: https:// www.lanacion.com.ar/2035689massa-quiere-instalar-12000-alarmasbarriales-como-parte-de-la-campanabonaerense 